\title{
Variability of Geomagnetic Field with Interplanetary Magnetic Field at Low, Mid and High Latitudes
}

\author{
S. Bhardwaj ${ }^{1}$, P. A. Khan ${ }^{2}$, R. Atulkar ${ }^{1}$, P. K. Purohit ${ }^{1 *}$ \\ ${ }^{1}$ National Institute of Technical Teacher's Training and Research, Bhopal- 462002 M.P., India \\ ${ }^{2}$ Department of Physics, Islamic University of Science and Technology, Pulwama-192122, J \\ \& K, India
}

Received 11 September 2017, accepted in final revised form 30 January 2018

\begin{abstract}
The fluctuations in the Interplanetary Magnetic Field significantly affect the state of geomagnetic field particularly during the Coronal Mass Ejection (CME) events. In the present investigation we have studied the influence of Interplanetary Magnetic Field changes on the geomagnetic field components at high, low and mid latitudes. To carry out this investigation we have selected three stations viz. Alibag $\left(18.6^{\circ} \mathrm{N}, 72.7^{\circ} \mathrm{E}\right)$, Beijing MT $\left(40.3^{\circ} \mathrm{N}, 116.2^{\circ} \mathrm{E}\right)$ and Casey $\left(66.2^{\circ} \mathrm{S}, 110.5^{\circ} \mathrm{E}\right)$ one each in the low, mid and high latitude regions. Then we selected geomagnetic storm events of three types namely weak ($50 \leq$ Dst $\leq-20)$, moderate $(100 \leq$ Dst $\leq-50)$ and intense (Dst $\leq-100 \mathrm{nT})$. In each storm category 10 events were considered. From our study we conclude that geomagnetic field components are significantly affected by the changes in the IMF at all the three latitudinal regions during all the storm events. At the same time we also found that the magnitude of change in geomagnetic field components is highest at the high latitudes during all types of storm events while at low and mid latitude stations the magnitude of effect is approximately the same.
\end{abstract}

Keywords: IMF; CME; Geomagnetic storm;Geomagnetic field.

(C) 2018 JSR Publications. ISSN: 2070-0237 (Print); 2070-0245 (Online). All rights reserved. doi: http://dx.doi.org/10.3329/jsr.v10i2.34509

J. Sci. Res. 10 (2), 133-144 (2018)

\section{Introduction}

The most important characteristic feature of the earth that distinguishes it from other planets of the solar system is that it is the only planet that supports life. The life supporting system is made possible by a protective shield of gases (atmosphere) and a cover of magnetic field around it. The protective cover of magnetic field around earth is confined in a specified region around it, known as magnetosphere. The magnetic field of

* Corresponding author: Purohit_pk2004@yahoo.com 
earth, known as geomagnetic field, is generated by the convective motion of molten outer metallic core by a mechanism known as geo-dynamo. In addition to the internal sources, the geomagnetic field has also sources in the earth's crust (Crustal Magnetization) as well as in the upper atmosphere. Due to changes in these sources whether internal or external, the magnetic field observable on the surface of earth does not remain steady, but undergoes significant variations and strong changes. The changes of internal origin (geodynamo) are usually regular and long term while as the changes due to external sources particularly those associated with upper atmosphere are short lived and irregular. In this paper we have investigated the changes occurring in the geomagnetic field at surface of earth due to the changes in the upper atmosphere.

The sun emits a continuous stream of charged particles at supersonic speeds, commonly known as solar wind. The solar wind travels in the direction of earth and eventually reaches the near-earth environment where its flow is interrupted by the presence of geomagnetic field [1]. The interaction of the solar wind with the geomagnetic field reshapes or restructures the dipolar magnetic field of earth into a cavity compressed from front side (sunside) and elongated into a tail like structure at the back (anti sunside) [2]. The solar wind also carries the sun's magnetic field which fills the entire interplanetary space and is known as Interplanetary Magnetic Field (IMF)[3,4]. The nature of interaction between the IMF and geomagnetic field depends on their relative orientation, particularly during extreme solar events $[5,6]$.

During extreme solar events like Coronal Mass Ejection (CME), filament and prominence eruptions, huge clouds of solar plasma containing frozen in magnetic field are thrown out [7-9]. Their interplanetary counterparts known as Interplanetary Coronal Mass Ejections (ICMEs) and other such structures have a fast rotating magnetic field, and on reaching the near-earth environment if they cause the IMF to be oriented northward, same as the direction of the geomagnetic field, then there is almost no interaction between the two. However, if the CME ejecta can manipulate the IMF to be oriented in southward direction i.e. opposite to the direction of the geomagnetic field, then the two fields can connect or effectively interact with each other like the opposite poles of two bar magnets. This linking of IMF with the terrestrial or earth's magnetic field is known as magnetic reconnection [10,11]. During the reconnection process efficient transfer of energy takes place from solar wind into magnetosphere as well as huge fluxes of charged particles enter the magnetosphere. These charged particles are deflected by the magnetic field of earth and circulate around the earth at a height of about $2-7 \mathrm{R}_{\mathrm{E}}$ (Earth Radii) [12], constituting a belt of current around earth, known as the ring current $[13,14]$. In addition some particles reach the high latitudinal ionosphere where they also develop other current system. The field aligned currents at the magnetosphere is another important current system resulting from this solar wind-Magnetospheric interaction. These current systems develop the magnetic field which can contribute to the geomagnetic field observed on the surface of earth. Among these various current systems, the important and major current system is the ring current. The ring current develops a magnetic field which is opposite to the geomagnetic field, hence when ring current is developed and intensifies, a sharp and 
intense reduction is observed in the horizontal component of the geomagnetic field on earth. This sharp and intense depression of the $\mathrm{H}$ component of earth's magnetic field is known as geomagnetic storm [15-17]. The amount of reduction in $\mathrm{H}$ component varies from place to place on earth as well as varies from storm to storm. In this reference, we have considered different places on earth as well as storms of different intensities to know the nature of variation and amount of decrease at different places during different storms. Some studies have been conducted in the past to investigate how the variations in IMF during geomagnetic storm events cause the variations in the geomagnetic field like a cause-effect relationship [18].

The effects of Interplanetary Magnetic Field on the H component of geomagnetic field during three geomagnetic storm events have been studied by Devi and his team and they concluded that $\mathrm{H}$ component had no significant deviations when IMF Bz was positive, and significant variation of $\mathrm{H}$ component were recorded during the negative IMF $\mathrm{Bz}$ conditions only, near sub-auroral zone [19]. It is observed that geomagnetic field components vary with interplanetary magnetic field when the later is oriented in southward direction [20]. They observed that the variations are larger at southern hemisphere compared to the northern hemisphere. Messanga et al. examined the variability of $\mathrm{H}$ component of geomagnetic field in Central African sector and found that the scattering of $\mathrm{H}$ component of magnetic field variation is more during disturbed conditions as compared to quiet condition [21]. The geomagnetic field fluctuations triggered by magnetic clouds having fast rotating magnetic fields were studied at low and polar cap by Villante et al. and observed similar results [22]. Rastogi found that during heavy storm, variations in H component near the earth's surface are higher at stations closer to magnetic equator [23]. The similar results have been found in some other studies as well [24-28].

\section{Data Selection}

We intend to study the influence of IMF on the geomagnetic field at high, mid and low latitudinal regions during the geomagnetic storms of different intensities The selected station are Alibag $\left(18.6^{\circ} \mathrm{N}, 72.7^{\circ} \mathrm{E}\right)$, Beijing MT $\left(40.3^{\circ} \mathrm{N}, 116.2^{\circ} \mathrm{E}\right)$ and Casey $\left(66.2^{\circ} \mathrm{S}\right.$, $110.5^{\circ} \mathrm{E}$ ) such that Alibag is the low latitude station, Beijing MT is the mid latitude station and similarly Casey is the high latitude station. In present work short names ABG, BMT and CAS have been used for Alibag, Beijing MT and Casey respectively.We selected geomagnetic storms of three intensities on the basis of key thresholds of Dst index. The geomagnetic storms with $-50 \leq \mathrm{Dst} \leq-20$ were chosen as weak storms, the geomagnetic storms with $100 \leq \mathrm{Dst} \leq-50$ were designated as moderate storms while as storms with Dst $\leq$ $100 \mathrm{nT}$ were categorized as intense storms. In each of the three categories we have considered 10 separate events. We have used the hourly values of Dst index taken from the World Data Center, kyoto, for the selected events. We have used two sets of magnetic field data taken from different sources. One set of data comprises the interplanetary magnetic field components and the other set is the geomagnetic field components. For 
obtaining the data of IMF, we have used the space based observations. The IMF is measured by Magnetometers onboard Advanced Composition Explorer (ACE) spacecraft. The database contains the data of different levels in several time resolutions. For the present study we have used the data with one minute time resolution. Moreover, the data in GSM (Geocentric Solar Magnetospheric) System were utilized for the present study. The IMF has three directional components, two of which (Bx and By) are oriented parallel to the ecliptic plane. The third component $\mathrm{Bz}$ is perpendicular to the ecliptic plane and very important for characterizing the geoeffective character of solar wind. The resultant magnitude of the IMF (B) is also provided along with the components. We then computed the magnitude of enhancement/decrement in the $\mathrm{B}$ and $\mathrm{Bz}$ components during every event. The enhancement/decrement were computed from the quietest day of that month during which storm was observed i.e. by subtracting the quietest day values from the storm day values and have represented as $\Delta \mathrm{B}$ and $\Delta \mathrm{Bz}$ respectively. For obtaining the data of geomagnetic field we have used the ground based observations. The ground magnetic field of earth is recorded by magnetometers installed and operated at a number of ground stations. A huge database of this data is maintained by the National Geophysical Data Center (NGDC). For each event we have downloaded the data three days before and six days after the event date, so that event is completely covered. For each of the three stations the data consists of the X-component (north), Y-component (east) and the Zcomponent (vertical). From the values of $\mathrm{X}, \mathrm{Y}$ and $\mathrm{Z}$ components we have calculated the values of total intensity $\mathrm{F}$ and the horizontal component $\mathrm{H}$. After obtaining the values of $\mathrm{H}$ and $\mathrm{F}$ we then computed the increase/decrease in the $\mathrm{H}$ component during the each storm at all the three stations. The change in $\mathrm{H}$ component was computed from the quietest day of month in which storm occurred. The change was calculated by subtracting the quietest day values from the storm day values. These have been represented by $\Delta \mathrm{H}_{\mathrm{ABG}}, \Delta \mathrm{H}_{\mathrm{BMT}}$ and $\Delta \mathrm{H}_{\mathrm{CAS}}$ for Alibag, Beijing MT and Casey, respectively.

\section{Results and Discussion}

We begin the presentation of the results by first examining the temporal variation of the IMF and geomagnetic field components at the three stations individually. Fig. 1 shows the time profile of geomagnetic field components and IMF components at the low latitude station Alibag during one of storms of each category i.e. 24 August 2005, 22 January 2005 and 10 August 2005. The five bottom panels represent the variation of X, Y, Z, H and F components of the geomagnetic field while the two top panels show the changes in the IMF Bz and B components. In each panel the three curves correspond to the three storms. The red line represents the variation during the intense storm of 24 August 2005. The peak Dst value observed during this storm was $-184 \mathrm{nT}$. The blue line depicts the variation of the magnetic field components during the moderate storms of 22 January 2005. The peak Dst value observed during this storms was $-97 n$ T. Similarly the olive colored line indicates the variation during the weak storm of 10 August 2005. The peak Dst observed during this storm is $-47 \mathrm{nT}$. From the figure we can clearly notice that the IMF $\mathrm{Bz}$ 
undergoes a sharp decrease while the B experiences a sharp increase before the onset of storm event. The magnitude of increase/decrease is highest for intense storm event while least changes occur for a weak storm. The influence of the IMF changes can be immediately seen in the geomagnetic field components X, Y, Z, H and F at Alibag, as the sharp decrease or increase. The north component $\mathrm{X}$, horizontal component $\mathrm{H}$ and total intensity $\mathrm{F}$ undergo a decrease while the east component $\mathrm{Y}$ and vertical component $\mathrm{Z}$ experience an increase from the normal or average value. The changes in the $\mathrm{X}, \mathrm{H}$ and $\mathrm{F}$ components are quite large and clearly pronounced while the changes in the $\mathrm{Y}$ and $\mathrm{Z}$ components can be seen as small fluctuations. Amongst the three types of storms, it can be found that largest changes in the geomagnetic field components at Alibag occur during intense storms while the least changes occur during the weak storms similar to those of IMF changes. Therefore, we concluded that the changes in the IMF components significantly affect the variability of the geomagnetic components at low latitude station Alibag during all kinds of geomagnetic storms. However, the largest changes are found to occur during the intense storms while the least changes take place during weak storms. At the same time it was found that $\mathrm{X}, \mathrm{H}$ and $\mathrm{F}$ components undergo a decrease from their normal value while $\mathrm{Y}$ and $\mathrm{Z}$ components show increase from their normal value. Similar results were found for the other nine storms also. In the Fig. 1, the case of one of the storm of each category has been shown as an example. Fig. 2 shows the temporal changes in the geomagnetic field components and the IMF components during the storms of 24 August 2005, 22 January 2005 and 10 August 2005 at the mid latitude station Beijing MT. The red, blue and olive color lines represent the variation during the storms of 24 August 2005, 22 January 2005 and 10 August 2005, respectively. From Fig. 2 we find that the changes in the IMF Bz and B significantly affect the variation of the geomagnetic field components at mid latitude station. The $\mathrm{X}, \mathrm{Y}, \mathrm{H}$ and $\mathrm{F}$ components undergo a sharp decrease from their normal or average value during each of these events. However, the vertical component $\mathrm{Z}$ experiences an increase during all the three events. Moreover, it was found that the magnitude of change in the geomagnetic field components is highest during the intense storm of 24 August 2005 while the lowest changes can be observed during the weak storm of 10 August 2005.The peak values achieved by all the five geomagnetic components during the intense storm are significantly larger than the peak values achieved during weak or moderate storm. The peak values achieved during weak and moderate storms does not have a significant difference. At Alibag the Y component of geomagnetic field shows an increase while at Beijing it shows a decrease. However, the variation of other components is similar. Only the $\mathrm{Y}$ component shows a different nature. The variation of IMF Bz and $\mathrm{B}$ components and geomagnetic components $\mathrm{X}, \mathrm{Y}, \mathrm{Z}, \mathrm{H}$ and $\mathrm{F}$ at the high latitude station Casey during the storm events of 24 August 2005, 22 January 2005 and 10August 2005 are shown in Fig. 3.The red line represents the variation of two types of magnetic field components during the intense storm of 24 August 2005 while the blue and black represent the corresponding variation during the moderate and weak storm of 22 January 2005 and 10 August 2005 respectively. 


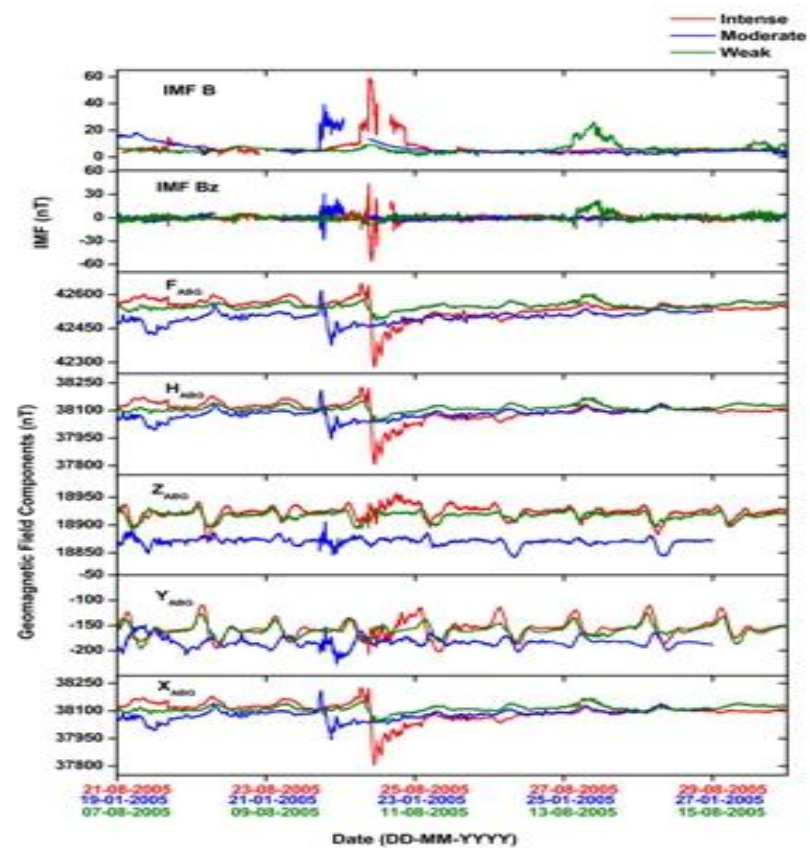

Fig. 1. The temporal variation of geomagnetic field Components with IMF components at Low Latitude Station Alibag, during three storms, one of each category.

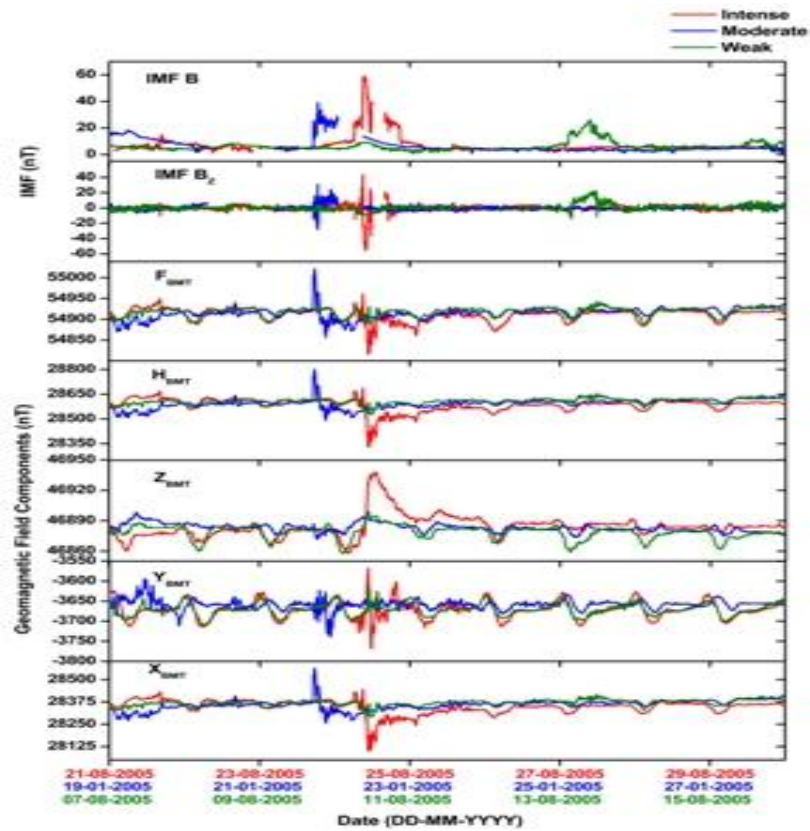

Fig. 2. The temporal variation of geomagnetic field Components with IMF components at Low mid Station Beijing, during three storms, one of each category. 


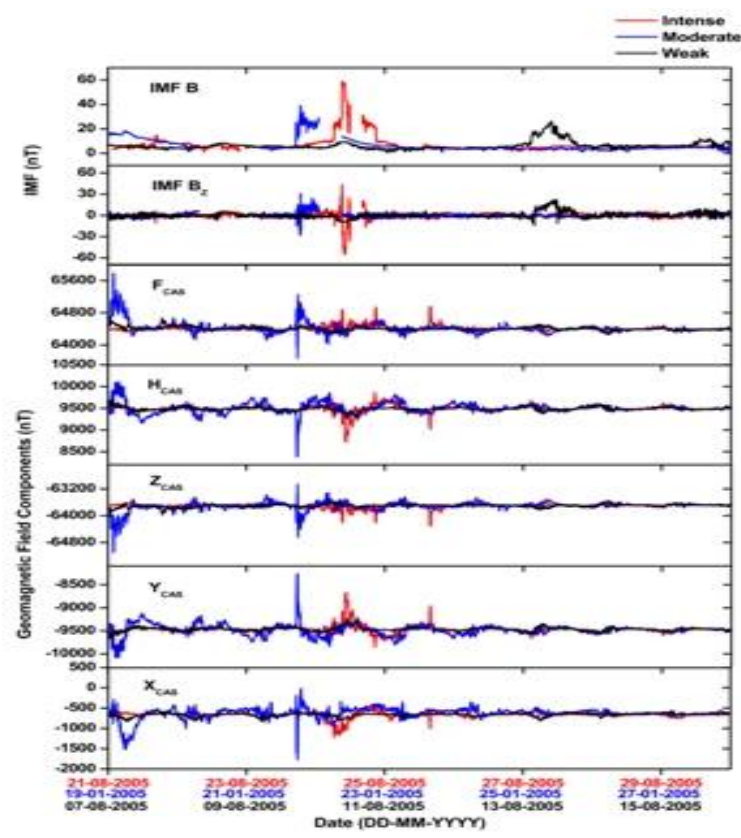

Fig. 3. The temporal variation of geomagnetic field Components with IMF components at high Latitude Station Casey, during three storms, one of each category.

From Fig. 3 we can easily notice that whenever IMF components undergo departures from their normal value the geomagnetic field components at Casey also exhibit sharp changes from their average or quiet time values, thereby clearly indicating that IMF strongly influences the state of geomagnetic field components particularly during the storm events. From Fig. 3 we can see that X, F and $\mathrm{H}$ decrease from their average values while $\mathrm{Y}$ and $\mathrm{Z}$ increase in their quiet time values. Thus the behavior of geomagnetic field components at high latitude station is similar to that of low latitude station Alibag. Moreover, the peak values of all the geomagnetic field components at Casey are higher during intense storm of 24 August 2005, while the peak values during moderate and intense storms of 22 January 2005 and 10 August 2005 are almost equal and two curves almost overlap.

To assess the magnitude of association between the IMF changes and the geomagnetic field we took the peak values of $\Delta \mathrm{B}, \Delta \mathrm{Bz}$ and $\Delta \mathrm{H}$ of all the selected events at the three selected stations and carried out the single regression analysis. The scatter plots and single regression analysis of $\Delta \mathrm{B}$ and $\Delta \mathrm{Bz}$ versus $\Delta \mathrm{H}$ during all the selected intense, moderate and weak storms at Alibag (low latitude) station is depicted in Fig. 4. A strong correlation was found to exist between the two variables, inferred from the correlation coefficients provided in each panel with red color. The correlation coefficients calculated between $\Delta \mathrm{Bz}$ and $\Delta \mathrm{H}$ are $0.78,0.81$ and 0.92 for intense moderate and weak storm respectively. Similarly the correlation coefficients between $\Delta \mathrm{B}$ and $\Delta \mathrm{H}$ are $0.91,0.87$ and 0.88 for 
intense moderate and weak storm respectively. The regression analysis of $\Delta \mathrm{H}$ with $\Delta \mathrm{B}$ and $\Delta \mathrm{Bz}$ at the mid latitude station Beijing MT during all the selected intense, moderate and weak storms is depicted in Fig. 5. A strong correlation is found to exist between the two types of variables at mid latitudes also. However, the correlation of $\Delta \mathrm{H}$ with $\Delta \mathrm{Bz}$ and $\Delta \mathrm{B}$ during moderate storms at Beijing MT is weaker than the same at Alibag. The correlation coefficients calculated between $\Delta \mathrm{Bz}$ and $\Delta \mathrm{H}$ are $0.76,0.63$ and 0.84 for intense, moderate and weak storm respectively.
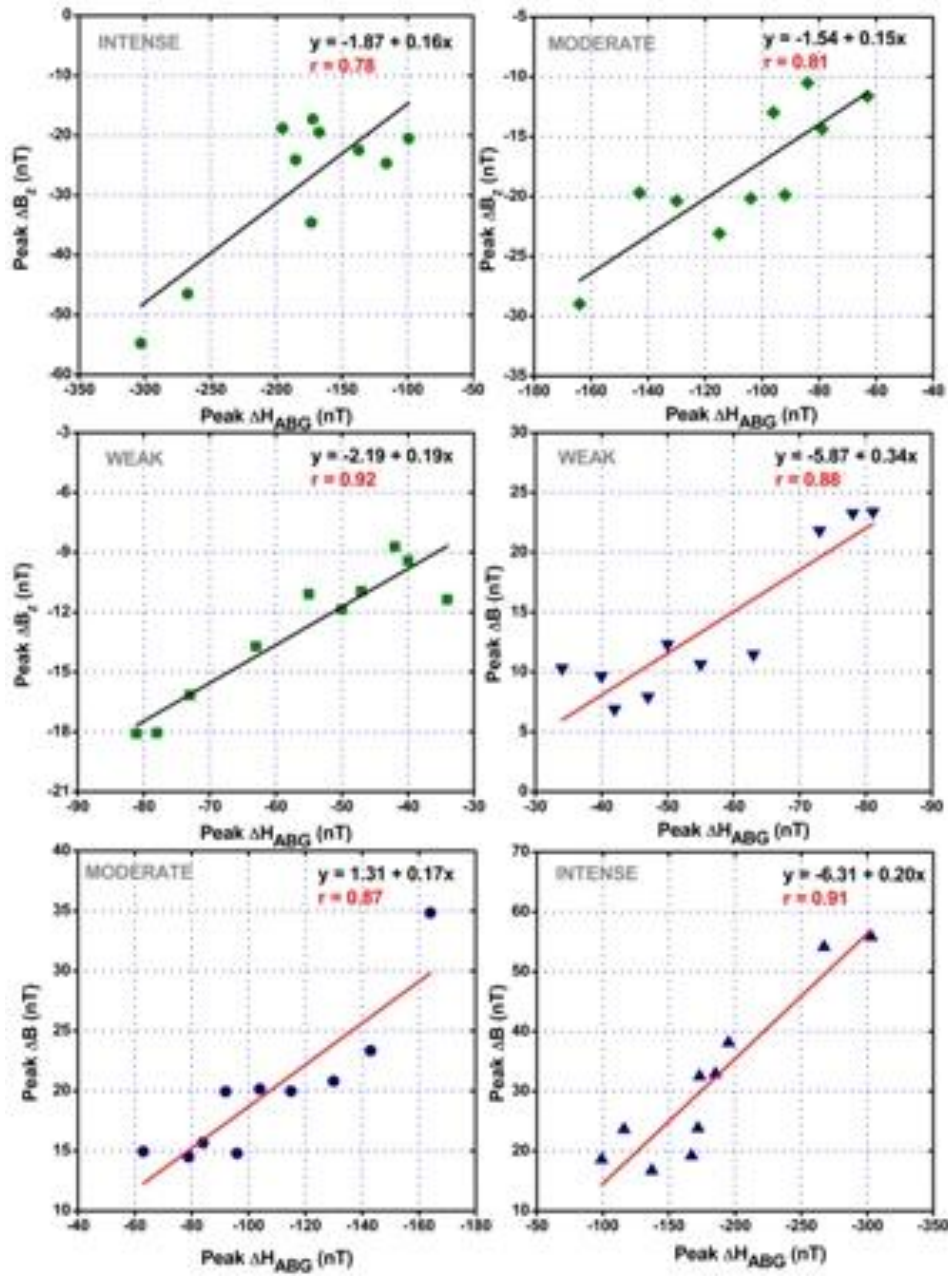

Fig. 4. The scatter plots and correlation of $\Delta \mathrm{B}$ and $\Delta \mathrm{Bz}$ versus $\Delta \mathrm{H}$ during all the selected intense, moderate and weak storms at Alibag.

Similarly the correlation coefficients between $\Delta \mathrm{B}$ and $\Delta \mathrm{H}$ are $0.91,0.76$ and 0.87 for intense moderate and weak storm, respectively. Finally, the regression analysis of $\Delta \mathrm{H}$ with $\Delta \mathrm{B}$ and $\Delta \mathrm{Bz}$ during all the selected intense, moderate and weak storms at high latitude station Casey is shown in Fig. 6. A moderate to strong correlation is found to exist 
between the two types of variables. The correlation coefficients calculated between $\Delta \mathrm{Bz}$ and $\Delta \mathrm{H}$ are $0.45,0.70$ and 0.83 for intense, moderate and weak storm respectively. Similarly the correlation coefficients between $\Delta \mathrm{B}$ and $\Delta \mathrm{H}$ are $0.80,0.87$ and 0.88 for intense, moderate and weak storm, respectively. At the high latitude station Casey we found that during intense storms the correlation between $\Delta \mathrm{Bz}$ and $\Delta \mathrm{H}$ is poor and the scatter of data points is also large. The reason for this could not be ascertained.Thus we conclude that changes in IMF correlate very strongly with the corresponding changes in the geomagnetic field at all the latitudes during all types of storms. A linear model fits very well between the two variables.
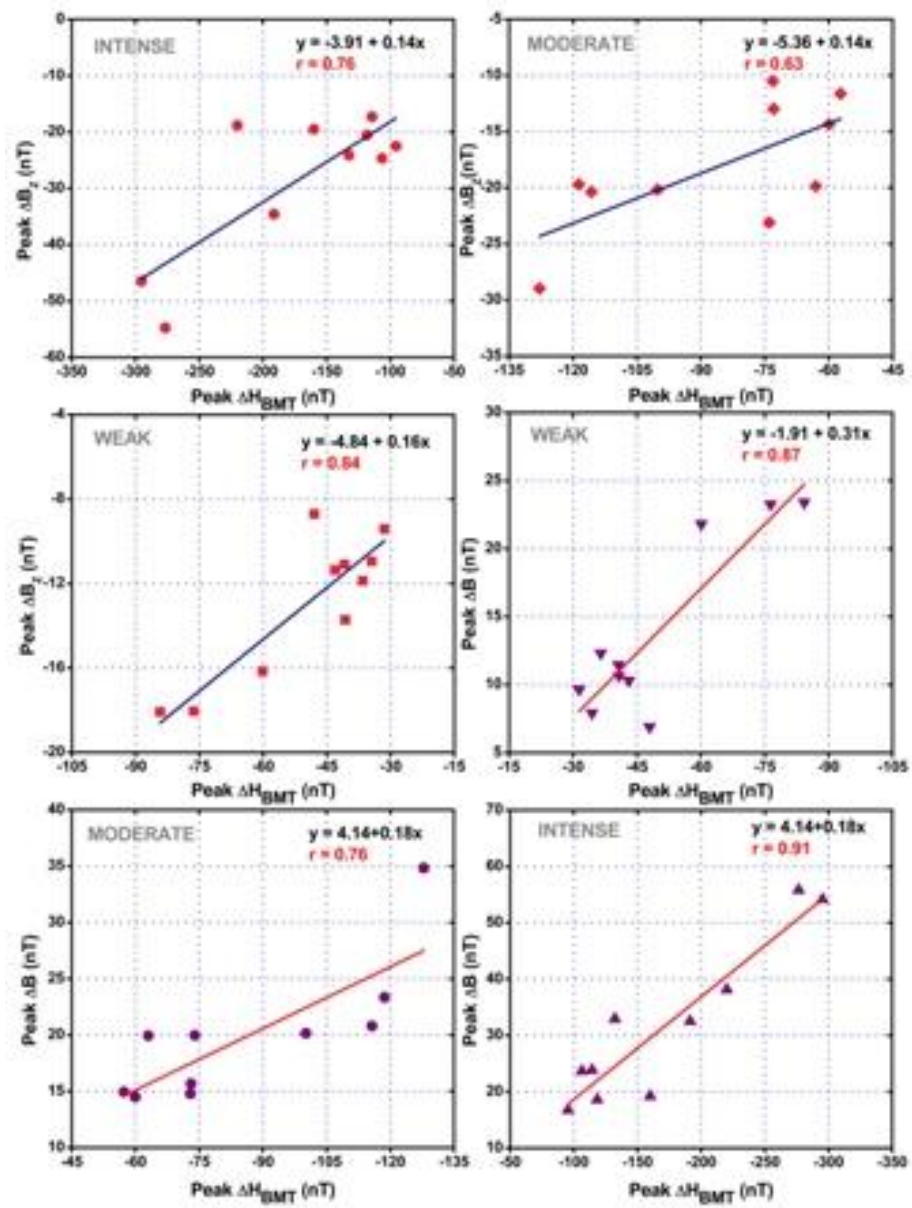

Fig. 5. The scatter plots and correlation of $\Delta \mathrm{B}$ and $\Delta \mathrm{Bz}$ versus $\Delta \mathrm{H}$ during all the selected intense, moderate and weak storms at Beijing. 

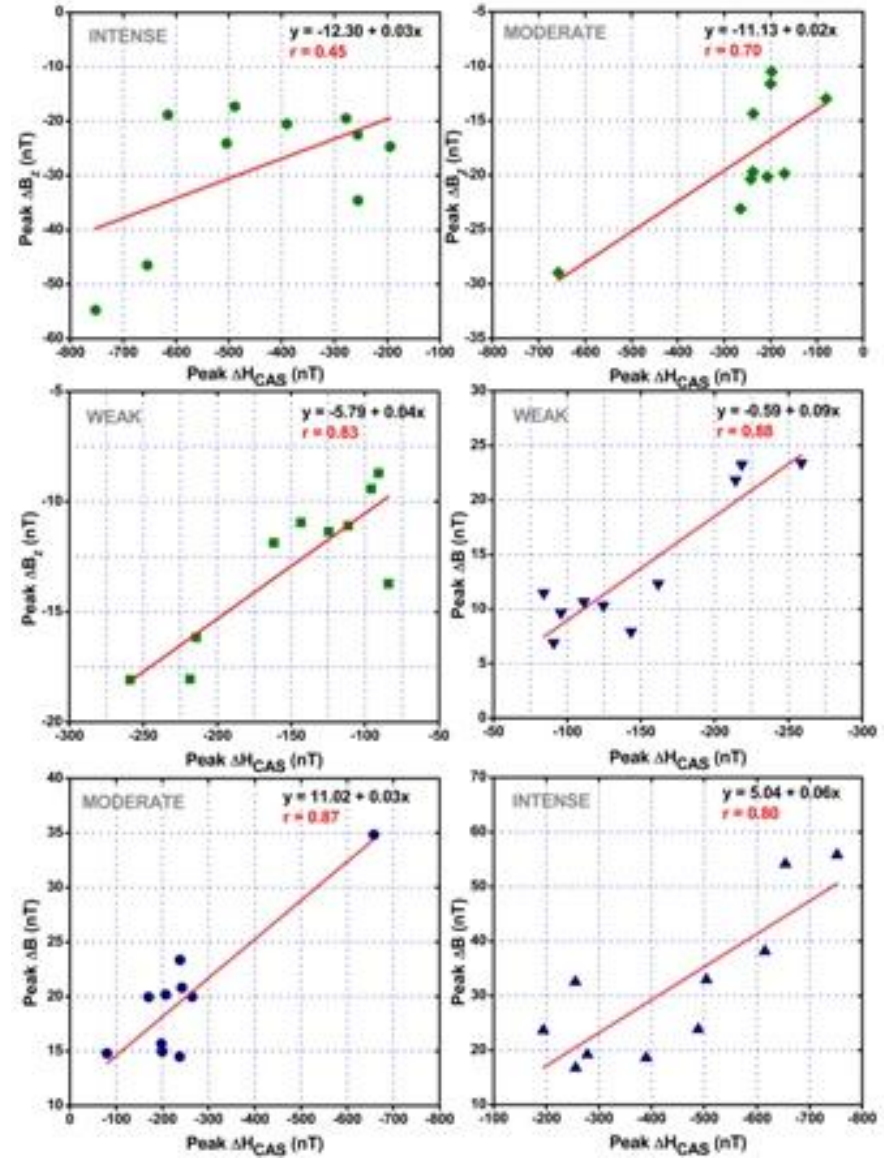

Fig. 6. The scatter plots and correlation of $\Delta \mathrm{B}$ and $\Delta \mathrm{Bz}$ versus $\Delta \mathrm{H}$ during all the selected intense, moderate and weak storms at Casey.

\section{Conclusion}

The main conclusions drawn from the present study are listed below:

- The changes in the IMF components significantly affect the variability of the geomagnetic components at all the three stations during all kinds of geomagnetic storms. However, the largest changes are found to occur during the intense storms while the least changes take place during weak storms.

- The largest enhancements/decrements are found to occur during intense storms while the least enhancements/decrements were observed during weak storms. The largest enhancements/decrements during a storm of particular category (intense, moderate or weak) were observed at high latitude station Casey while the enhancements/decrements at low and mid latitude stations were approximately same. 
- A strong correlation was found to exist between the peak values of enhancements/decrements of IMF and H components of geomagnetic field at all the stations during all kinds of geomagnetic storms. A good linear fit was found to exit between the peak values of IMF and H components of geomagnetic field at all the stations during all kinds of geomagnetic storms.

\section{Acknowledgment}

We thank teams of ACE MAG and World Data Center Kyoto and other, ground-based magnetic stations and developers of the NGDC database for the possibility to use data in our investigations.

\section{References}

1. A. J. Hundhausen, Physics and Chemistry in Space (Springer, New York, 1972).

2. S. Chapman and V. C. A. Ferraro, Terr. Magnetism Atmospheric Electricity 36, (1931).

3. V. Bothmer and R. Schwenn, Ann. Geophys. 16, 1 (1998). https://doi.org/10.1007/s00585-9970001-X

4. B. T. Tsurutani, W. D. Gonzalez, F. Tang, S. I. Akasofu, and E. J. Smith, J. Geophys. Res. 93, 8519 (1988).

5. S. I. Akasofu, Space Sci. Rev. 28, 121 (1981).https://doi.org/10.1007/BF00218810

6. J. T. Gosling, S. J. Bame, D. J. McComas, and J. L. Phillips, Geophys. Res. Lett. 17, 901 (1990). https://doi.org/10.1029/GL017i007p00901

7. N. Gopalswamy, L.Barbieri, G. Lu, S.P. Plunkett, and R.M. Skoug,Geophys. Res. Lett. 32, L03S01 (2005). https://doi.org/10.1029/2005GL022348

8. I. G. Richardson, E. W. Cliver, and H. V. Cane, J. Geophys. Res. 105, 203 (2000).

9. R. Schwenn, A. D. Lago, E. Huttunen, and W. D. Gonzalez, Ann. Geophys. 23, 1033 (2005). https://doi.org/10.5194/angeo-23-1033-2005

10. J. W. Dungey, Phys. Rev. Lett. 6, 47 (1961). https://doi.org/10.1103/PhysRevLett.6.47

11. W. I. Axford and C. O. Hines, Can. J. Phys. 39, 1433 (1961). https://doi.org/10.1139/p61-172

12. W. Baumjohann, Y. Kamide, and R. Nakamura, J. Geomagn. Geoelect. 48, 177 (1996). https://doi.org/10.5636/jgg.48.177

13. Y. Kamide, W. Baumjohann, I. A. Daglis, W. D. Gonzalez, M. Grande, J. A. Joselyn ,R. L. McPherron, J. L. Phillips, E. G. D. Reeves, G. Rostoker, A. S. Sharma, H. J. Singer, B. T. Tsurutani, and V. M. Vasyliunas, J. Geophys. Res. 103, 17705 (1998). https://doi.org/10.1029/98JA01426

14. I. A. Daglis, R. M. Thorne, W. Baumjohann, and S. Orsini, Rev. Geophys. 37, 407 (1999). https://doi.org/10.1029/1999RG900009

15. C. T. Russell, R. L. McPherron, and R. K. Burton, J. Geophys. Res. 79, 1105 (1974). https://doi.org/10.1029/JA079i007p01105

16. R. K. Burton, R. L. McPherron, and C. T. Russell, J. Geophys. Res. 80, 4204 (1975). https://doi.org/10.1029/JA080i031p04204

17. W. D. Gonzalez, J. A. Joselyn, Y. Kamide, H. W. Kroehl, G. Rostoker, B. T. Tsurutani and V. M. Vasyliunas, J. Geophys. Res. 99, 5771 (1994). https://doi.org/10.1029/93JA02867

18. R. P. Kane, J. Geophys. Res. 110, A02213 (2005).

19. R. Devi, S. Dubey, S. Saini, B. Devi, A. Dhar, S. K. Vijay, and A. K. Gwal, J. Astrophys. Astr. 29, 281 (2008). https://doi.org/10.1007/s12036-008-0037-7

20. B. Devi, S. Dubey, S. Saini, R. Devi, R. Wahi, A. Dhar, S. K. Vijay, and A. K. Gwal, J. Astrophys. Astr. 29, 275 (2008). https://doi.org/10.1007/s12036-008-0036-8

21. E. H. Messanga, D. C. M. Kosh and B. C. Mbane, J. Geosci. 5, 1190 (2014). 


\section{Geomagnetic Field with Interplanetary Magnetic Field}

22. U. Villante, P. Francia, S. Lepidi, M. De. Lauretis, E. Pietropaolo, L. Cafarella, A. Meloni, A. J. Lazarus, R. P. Lepping, and F. Marini, Geophys. Res. Lett. 25, 2593 (1998).

https://doi.org/10.1029/98GL00335

23. R. G. Rastogi, Earth Planet Space 58, 1 (2006). https://doi.org/10.1186/BF03351907

24. R. P. Lepping, J. Geophys. Res. Solar. Phys. 96, 9425 (1991).

25. S. Lepidi, P. Francia, U. Villante, A. Meloni, A. J. Lazarus, and R. P. Lepping, Ann. Geophysicae 17, 1245(1999). https://doi.org/10.1007/s005850050850

26. B. Chandel, Intl. J. Recent Dev. Eng. Technol. 3, 142 (2014).

27. L. I. Gromova and S. V. Gromov, Phy. of Auroral Phenomena - Proc. XL Annual Seminar, Apatity, (2017) pp. 19-22. 